Check for updates

Cite this: J. Mater. Chem. C, 2021, 9, 14916

Received 6th September 2021, Accepted 7th October 2021

DOI: $10.1039 / \mathrm{d} 1 \mathrm{tc04231a}$

rsc.li/materials-c

\section{Spin structures and band gap reduction of high-pressure triple perovskite $\mathrm{Mn}_{3} \mathrm{MnTa}_{2} \mathrm{O}_{9} \dagger$}

\author{
Elena Solana-Madruga, (D) *a Clemens Ritter, ${ }^{b}$ Olivier Mentré (iD a and \\ Ángel M. Arévalo-López (iD *a
}

\begin{abstract}
Herein we report the second transition-metal-only triple perovskite $\mathrm{Mn}_{3} \mathrm{MnTa}_{2} \mathrm{O}_{9}$, from high pressurehigh temperature transformation of $\mathrm{Mn}_{4} \mathrm{Ta}_{2} \mathrm{O}_{9}$. It shows 1:2 $\mathrm{Mn}: \mathrm{Ta} \mathrm{B}$-site order and a complex antiferromagnetic behavior with a collinear structure that modulates into a spin density wave. The high pressure phase presents a $25 \%$ band gap reduction compared to its multiferroic precursor, recoverable above $625^{\circ} \mathrm{C}$.
\end{abstract}

\section{Introduction}

The flexibility of transition metal (TM) perovskite oxides $\left(\mathrm{ABO}_{3}\right.$, $\mathrm{Pv}$ ) allows accommodation of a wide variety of elements into both A and B sites and thus tuning of their promising technological applications. ${ }^{1,2}$ Different types of cation ordered derivatives can also be obtained and their physical properties enhanced, for instance $\mathrm{Sr}_{2} \mathrm{FeMoO}_{6}$ (double perovskite $\mathrm{DPv}$, 1:1 B-site ordering), where the Fe-Mo cation order promotes its room temperature colossal magnetoresistance. ${ }^{3}$ Exotic perovskites with small TM ions at the A-sites are usually stabilized under high-pressure, as in $\mathrm{CaCu}_{3} \mathrm{Fe}_{2} \mathrm{Re}_{2} \mathrm{O}_{12}$ (quadruple perovskite $\mathrm{QPv}$ with 1:3 A and 1:1 B site ordering). ${ }^{4}$

The growing family of A-site manganites is under intensive study, since the stabilization of $\mathrm{Mn}$ into the A-site in the perovskite structure via high-pressure (HP) provides a rich playground of potential spin, orbital and charge orders. Among them, simple (Pv, only $\left.\mathrm{MnVO}_{3}\right){ }^{5}$ double (DPv, e.g. $\left.\mathrm{Mn}_{2} \mathrm{FeReO}_{6}\right){ }^{6}$ doubly ordered (also known as double DDPv, e.g. $\mathrm{MnRMnSbO}_{6}$ with $\mathrm{R}=$ rare earth), ${ }^{7}$ quadruple $\left(\mathrm{QPv}, \text { e.g. } \mathrm{MnMn}_{3} \mathrm{Mn}_{4} \mathrm{O}_{12}\right)^{8,9}$ and only very recently triple (TPv, only $\mathrm{Mn}_{3} \mathrm{MnNb}_{2} \mathrm{O}_{9}$ with $1: 2 \mathrm{~B}$ site ordering $)^{10}$ perovskite phases have been reported.

In the present study we prepared at high pressure and temperature $\mathrm{Mn}_{3} \mathrm{MnTa}_{2} \mathrm{O}_{9}$, the second transition-metal-only $\mathrm{A}_{3} \mathrm{BB}_{2}{ }_{2} \mathrm{O}_{9}$ triple perovskite, from the room pressure (RP) magnetoelectric $\mathrm{Mn}_{4} \mathrm{Ta}_{2} \mathrm{O}_{9}$ at $8 \mathrm{GPa}$ and $1100{ }^{\circ} \mathrm{C}$. A comparative study with the closely related $\mathrm{HP}-\mathrm{Mn}_{3} \mathrm{MnNb}_{2} \mathrm{O}_{9}$ is presented

\footnotetext{
${ }^{a}$ Univ. Lille, CNRS, Centrale Lille, ENSCL, Univ. Artois, UMR 8181 - UCCS - Unité de Catalyse et Chimie du Solide, F-5900o Lille, France.

E-mail: elena.solanamadruga@univ-lille.fr, angel.arevalo-lopez@univ-lille.fr

${ }^{b}$ Institut Laue-Langevin, Avenue des Martyrs 71, 32042, Grenoble Cedex, France

$\dagger$ Electronic supplementary information (ESI) available: Supporting figures and tables. See DOI: 10.1039/d1tc04231a
}

here. Both isostructural compounds have a complex magnetic behavior, with three subsequent transitions at $T_{\mathrm{N}}=52 \mathrm{~K}$, $T_{\mathrm{M}}=30.5 \mathrm{~K}$ and $T_{\mathrm{L}}=6 \mathrm{~K}$ for Ta $(52.1,27.8$ and $4.8 \mathrm{~K}$ respectively for the $\mathrm{Nb}$ compound), where $\mathrm{Mn}^{2+}$ spins order into a collinear antiferromagnetic (AFM) structure that modulates into a spin density wave (SDW) and locks-in at lower temperature as revealed by neutron powder diffraction (NPD). The band gap as measured from UV-vis and calculated from DFT for the new HP- $\mathrm{Mn}_{3} \mathrm{MnTa}_{2} \mathrm{O}_{9}$ shows a reduction of $25 \%$ when compared to its room pressure precursor and we argue that this is due to the change in connectivity between both polymorphs offering a promising approach to adjust to ideal values for photovoltaic applications.

\section{Results and discussion}

Structural characterization was performed from the Rietveld fit against high resolution NPD data $(\lambda=1.54 \AA$, collected on D20 @ ILL). Fig. 1a shows the structural features of the TPv model refined using Full Prof suite ${ }^{11}$ and summarized in Table 1. HP- $\mathrm{Mn}_{3} \mathrm{MnTa}_{2} \mathrm{O}_{9}$ crystallizes with the acentric monoclinic $C c$ symmetry with $a=9.8992(3) \AA, b=5.3267(2) \AA$, $c=13.2472(5) \AA$ and $\beta=92.736(3)^{\circ}$ cell parameters. As for HP$\mathrm{Mn}_{3} \mathrm{MnNb}_{2} \mathrm{O}_{9}{ }^{10}$ the $C 2 / c$ symmetry was tested and found in worse agreement (ESI $\dagger$ ), the superstructure peaks (200), (002) and (110) support the refined $C c$ model (ESI $\dagger$ Fig. SF1). The refined structure shows perfect $1: 2$ cation order between $\mathrm{Mn}^{2+}$ $\left(\mathrm{Mn}_{2}\right.$, blue $)$ and $\mathrm{Ta}^{5+}\left(\mathrm{Ta}_{1}\right.$ and $\mathrm{Ta}_{2}$, orange $)$ among the $\mathrm{B}$ sites (being isostructural to $\mathrm{HP}-\mathrm{Mn}_{3} \mathrm{MnNb}_{2} \mathrm{O}_{9}$ ), see Fig. 1b. $\mathrm{Mn}-\mathrm{O}$ distances up to $3.5 \AA$ confirm octahedral coordination for Mn2, with all bond lengths between $1.99 \AA$ and $2.28 \AA$ A. Otherwise, Mn1 (black), Mn3 (red) and Mn4 (green) show 12-, 11- and 10 -fold coordination respectively, according to their location 

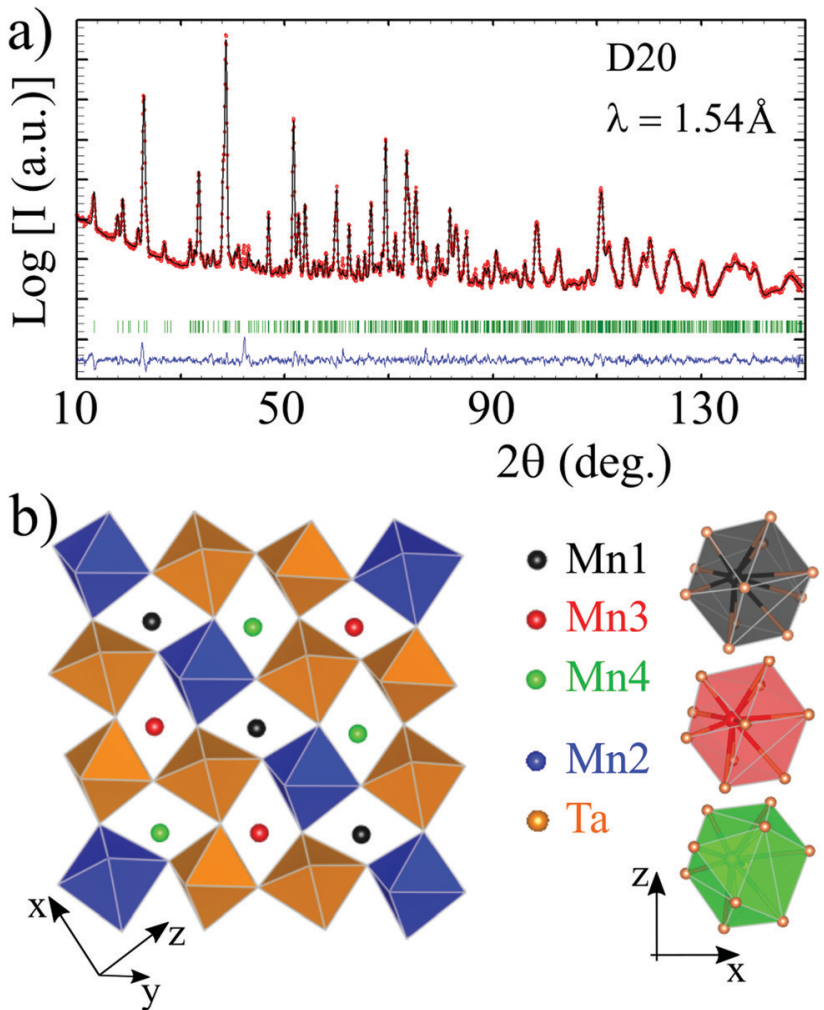

Fig. 1 (a) Rietveld fit against $300 \mathrm{~K}$ high resolution NPD data of HP$\mathrm{Mn}_{3} \mathrm{MnTa}_{2} \mathrm{O}_{9}$. (b) Refined TPv crystal structure. One (11-2) plane with the B-site order of Mn2 and Ta is shown on the left panel and 12-, 11- and 10 -fold coordination polyhedra of $\mathrm{Mn}$ A sites on the right panel.

Table 1 Atomic positions (all Wyckoff 4a sites fully occupied) of HP$\mathrm{Mn}_{3} \mathrm{MnTa}_{2} \mathrm{O}_{9}$ refined from the $300 \mathrm{~K}$ high resolution NPD data. Space group $C c$ and cell parameters $a=9.8992(3) \AA, b=5.3267(2) \AA$, $c=13.2472(5) \AA$ and $\beta=92.736(3)^{\circ}$. Thermal parameters constrained for cations and anions refine to 0.53 (5) and $0.54(2) \AA^{2}$ respectively

\begin{tabular}{|c|c|c|c|c|c|c|}
\hline Site & \multicolumn{2}{|c|}{$x$} & \multicolumn{2}{|c|}{$\mathrm{y}$} & & $\mathrm{z}$ \\
\hline Mn1 & \multicolumn{2}{|c|}{$0.728(2)$} & \multicolumn{2}{|c|}{$0.494(4)$} & & $0.428(1)$ \\
\hline $\mathrm{Mn} 2$ & \multicolumn{2}{|c|}{$0.440(3)$} & \multicolumn{2}{|c|}{$0.479(3)$} & & $0.476(2)$ \\
\hline $\mathrm{Mn}^{a}{ }^{a}$ & \multicolumn{2}{|c|}{0.394} & \multicolumn{2}{|c|}{0.5} & & 0.757 \\
\hline Mn4 & \multirow{2}{*}{\multicolumn{2}{|c|}{$\begin{array}{l}0.551(2) \\
0.105(1)\end{array}$}} & \multirow{2}{*}{\multicolumn{2}{|c|}{$\begin{array}{l}-0.012(4) \\
0.508(3)\end{array}$}} & & $0.589(1)$ \\
\hline Ta1 & & & & & & $0.823(1)$ \\
\hline Ta2 & \multicolumn{2}{|c|}{$0.770(1)$} & \multicolumn{2}{|c|}{$0.511(2)$} & & $0.652(1)$ \\
\hline $\mathrm{O} 1$ & \multicolumn{2}{|c|}{$0.724(2)$} & \multicolumn{2}{|c|}{$0.698(2)$} & & $0.776(1)$ \\
\hline $\mathrm{O} 2$ & \multicolumn{2}{|c|}{$0.194(1)$} & \multicolumn{2}{|c|}{$0.687(2)$} & & $0.697(1)$ \\
\hline $\mathrm{O} 3$ & \multirow{2}{*}{\multicolumn{2}{|c|}{$\begin{array}{l}0.111(1) \\
0.853(1)\end{array}$}} & \multicolumn{2}{|c|}{$0.864(3)$} & & $0.070(1)$ \\
\hline $\mathrm{O} 4$ & & & \multirow{2}{*}{\multicolumn{2}{|c|}{$\begin{array}{l}0.337(2) \\
0.688(2)\end{array}$}} & & $0.538(1)$ \\
\hline O5 & \multicolumn{2}{|c|}{$0.514(1)$} & & & & $0.367(1)$ \\
\hline O6 & \multicolumn{2}{|c|}{$0.563(1)$} & \multicolumn{2}{|c|}{$0.186(2)$} & & $0.449(1)$ \\
\hline $\mathrm{O} 7$ & \multicolumn{2}{|c|}{$0.767(1)$} & \multicolumn{2}{|c|}{$0.864(3)$} & & $0.395(1)$ \\
\hline $\mathrm{O} 8$ & \multicolumn{2}{|c|}{$0.450(2)$} & \multicolumn{2}{|c|}{$0.885(1)$} & & $0.744(1)$ \\
\hline \multirow[t]{2}{*}{ O9 } & \multicolumn{2}{|c|}{$0.387(1)$} & \multicolumn{2}{|c|}{$0.294(2)$} & & $0.624(1)$ \\
\hline & Mn1 & Mn2 & Mn3 & Mn4 & Ta1 & Ta2 \\
\hline$\langle\lambda\rangle$ & 1.086 & 1.016 & 1.089 & 1.060 & 1.009 & 1.012 \\
\hline $10^{3} \Delta$ & 10.4 & 37.7 & 5.6 & 8.1 & 4.1 & 3.8 \\
\hline$\sigma^{2}\left(\mathrm{deg}^{2}\right)$ & 254.2 & 46.5 & 266.2 & 182.6 & 20.7 & 31.3 \\
\hline BVS & 1.94 & 2.45 & 2.03 & 2.07 & 4.67 & 4.71 \\
\hline
\end{tabular}

${ }^{a}$ Mn3 site used as a cell reference. into A sites of the $\mathrm{TPv}$ structure. The structural distortion parameters, including $\mathrm{a}^{-} \mathrm{b}^{-} \mathrm{c}^{-}$tilt angles $\left(\Phi_{1}=18.90^{\circ}\right.$, $\Phi_{2}=23.20^{\circ}$ and $\Phi_{3}=24.25^{\circ}$ ) and polyhedral distortions (quadratic elongation and bond angle variance, see Table 1 ) are of the same order of magnitude as those observed for the related HP$\mathrm{Mn}_{3} \mathrm{MnNb}_{2} \mathrm{O}_{9}$ TPv. $^{10}$ This suggests that A-site manganites with 1:2 B-site order could generally stabilize much greater distortions with respect to $\mathrm{Pv}, \mathrm{DPv}$ and $\mathrm{QPv}$ materials (SF2, ESI $\dagger$ ). Bond Valence Sum (BVS) calculations confirm nominal $\mathrm{Mn}^{2+}$ and $\mathrm{Ta}^{5+}$ oxidation states, with compensated mismatches among the B-site cations reflecting the strain in the structure and the necessity to stabilize it at high pressure.

A comparative study of the crystal structures of HP$\mathrm{Mn}_{3} \mathrm{MnB}_{2}{ }_{2} \mathrm{O}_{9}$ with $\mathrm{B}^{\prime}=\mathrm{Ta}$ and $\mathrm{Nb}$ (see Table 2) indicates their main differences concern coordination numbers of MnA sites and tilt angles. Higher A-site coordination is found for $\mathrm{B}^{\prime}=\mathrm{Ta}$, supporting the perovskite-related structure. Smaller $\Phi_{1}$ and $\Phi_{2}$ while larger $\Phi_{3}$ values compared with those in HP$\mathrm{Mn}_{3} \mathrm{MnNb}_{2} \mathrm{O}_{9}$, agree with the relative lattice parameters, two of which are longer for $\mathrm{HP}-\mathrm{Mn}_{3} \mathrm{MnTa}_{2} \mathrm{O}_{9}$. Similar unit cell volumes reflect the close synthesis conditions for both compounds, coherently with their equivalent ionic radii $(0.64 \AA$ for both $\mathrm{Nb}^{5+}$ and $\left.\mathrm{Ta}^{5+}\right){ }^{12}$ This is also reflected in similar global distortion parameters which confirms their close stability, suggesting other related high pressure compounds should be accessible from HPHT phase transition from the $\mathrm{A}_{4} \mathrm{~B}_{2} \mathrm{O}_{9}$ niobates and tantalates first reported by Bertaut et al. ${ }^{13}$ Consequently, new complex HP-TPv are currently under study.

Magnetic susceptibility data (top panel in Fig. 2) show two clear magnetic transitions at $T_{\mathrm{N}}=52 \mathrm{~K}$ and $T_{\mathrm{M}}=30.5 \mathrm{~K}$. These transitions are also observed as $\lambda$ peaks in heat capacity measurements (see SF2, ESI $\dagger$ for derivative curves and $T_{\mathrm{N}}$ and $T_{\mathrm{M}}$ assignment). A low temperature anomaly $\left(T_{\mathrm{L}}=6 \mathrm{~K}\right)$ is assigned to a lock-in transition of the modulated magnetic phase, in accordance to NPD results as described below (Fig. 2 middle and bottom panels). Curie-Weiss fit to the inverse susceptibility above $150 \mathrm{~K}$ results in an effective magnetic moment of $6.0(1) \mu_{\mathrm{B}} / \mathrm{Mn}^{2+}$, in good agreement with the expected value of $5.92 \mu_{\mathrm{B}} / \mathrm{Mn}^{2+}$, and $\theta=-237(1) \mathrm{K}$, suggesting dominant AFM interactions with strong magnetic frustration ( $f=|\theta| / T_{\mathrm{N}}=4.6(1)$. A similar behavior was observed for HP$\mathrm{Mn}_{3} \mathrm{MnNb}_{2} \mathrm{O}_{9}$, the main difference between both compounds being the clear lambda-like transition observed in the $\mathrm{Nb}$ compound at $T_{\mathrm{L}}$. Here, this lock-in is more evident from NPD data (vide infra) while the derivative of heat capacity data $(\mathrm{SF} 2, \mathrm{ESI} \dagger)$ shows a broad maximum.

Table 2 Compared main structural features of $\mathrm{HP}-\mathrm{Mn}_{3} \mathrm{MnB}_{2}^{\prime} \mathrm{O}_{9}\left(\mathrm{~B}^{\prime}=\mathrm{Nb}, \mathrm{Ta}\right)$

\begin{tabular}{lll}
\hline $\mathrm{B}^{\prime}$ & $\mathrm{Nb}$ & $\mathrm{Ta}$ \\
\hline MnA coordination & $10,10,8$ & $12,11,10$ \\
$\Phi_{1}, \Phi_{2}, \Phi_{3}\left(^{\circ}\right)$ & $20,25,16$ & $19,23,24$ \\
$a(\AA)$ & $9.9054(5)$ & $9.8992(3)$ \\
$b(\AA)$ & $5.3097(2)$ & $5.3267(2)$ \\
$c(\AA)$ & $13.2052(7)$ & $13.2472(5)$ \\
$\beta\left({ }^{\circ}\right)$ & $92.772(6)$ & $92.736(3)$ \\
$V\left(\AA^{3}\right)$ & $693.72(3)$ & $697.73(5)$
\end{tabular}




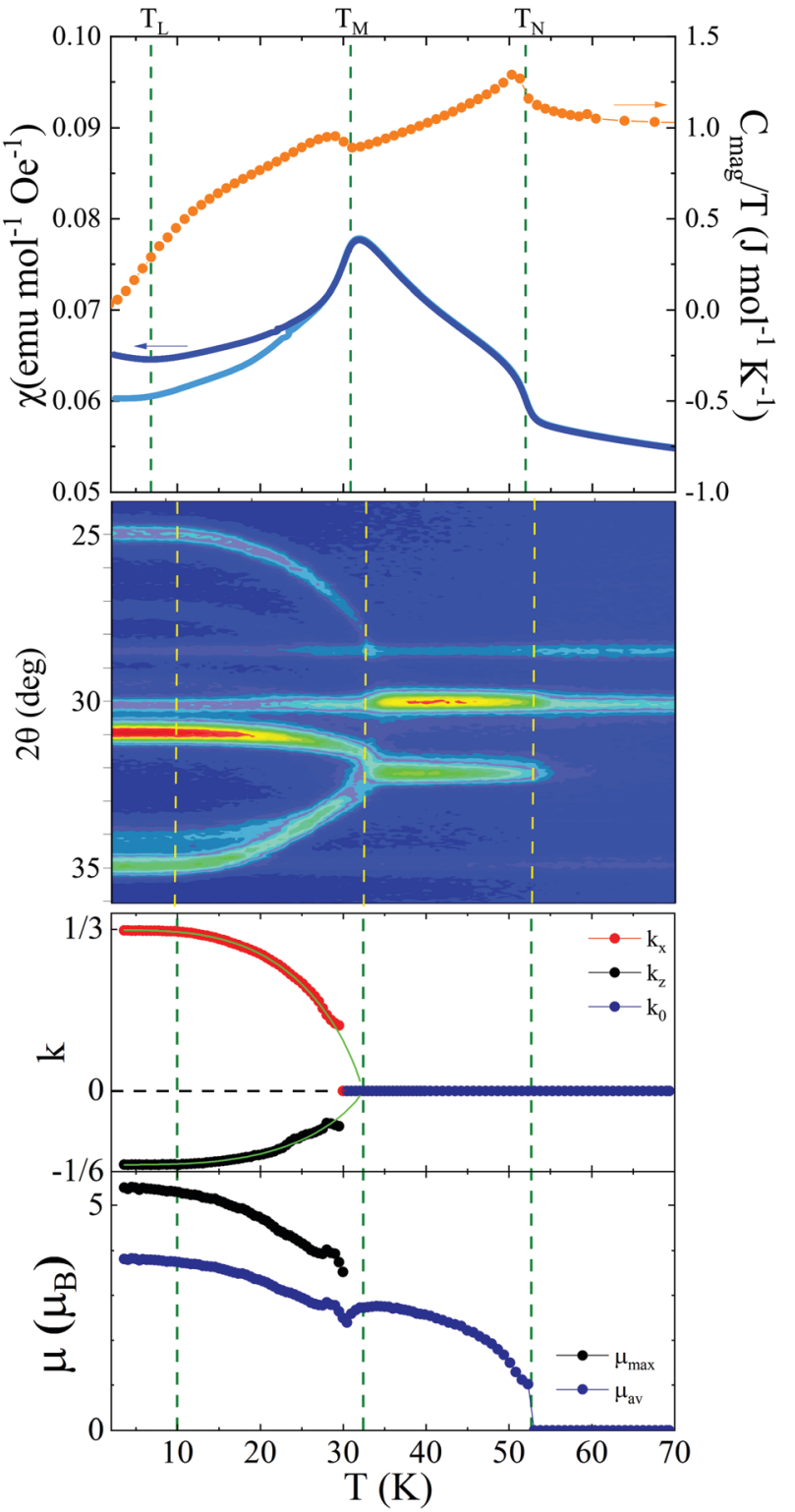

Fig. 2 Temperature dependence of magnetic susceptibility and heat capacity (top panel), neutron diffraction (middle) and refined propagation vector and magnetic moment (bottom). Dashed lines mark $T_{N}, T_{M}$ and $T_{L}$ transition temperatures. Green lines in bottom panel show the fit of $k$ vectors to a critical law. $\mu_{\max }$ stand for maximum values in the SDW phase and $\mu_{\mathrm{av}}$ for averaged $(\mu / 2 \pi)$ magnetic moments.

The thermal evolution of NPD data $(\lambda=2.41 \AA$, D20@ILL) focused on the $24-36^{\circ} 2 \theta$ region is depicted in the middle panel of Fig. 2. These data confirm that HP- $\mathrm{Mn}_{3} \mathrm{MnTa}_{2} \mathrm{O}_{9}$ undergoes an AFM transition below $54 \mathrm{~K}$, marked with a dashed line. A coherent increase of the intensity of these magnetic peaks is observed down to $32 \mathrm{~K}$ (both $T_{\mathrm{M}}$ and $T_{\mathrm{N}}$ show a $2 \mathrm{~K}$ difference respect to bulk properties, usual from experimental details), where the magnetic susceptibility describes a maximum, and a sharp transition occurs, involving the immediate shift of the magnetic peaks. All magnetic peaks in the $T_{\mathrm{N}}>T>T_{\mathrm{M}}$ temperature range can be indexed with the propagation vector

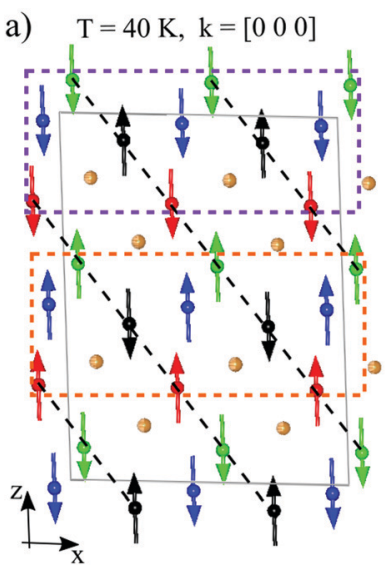

b) $\mathrm{T}=1.5 \mathrm{~K}, \mathrm{k}_{\mathrm{L}}=\left[\frac{1 / 30}{0}-1 / 6\right]$

Fig. 3 (a) Magnetic structure of $\mathrm{HP}-\mathrm{Mn}_{3} \mathrm{MnTa}_{2} \mathrm{O}_{9}$ at $40 \mathrm{~K}$ with $k_{0}=\left[\begin{array}{lll}0 & 0 & 0\end{array}\right]$. AFM (101) MnA planes (red-green-black) are highlighted with black dashed lines. Orange spheres represent Ta sites and the dashed purple and orange boxes highlight sections of the nuclear cell with different sine patterns at low temperature. (b) Schematic representation of UUODDO and sinusoidal waves at $1.5 \mathrm{~K}$ with $k_{\mathrm{L}}=[1 / 30-1 / 6]$, where $\mathrm{Mn} 2$ (blue)/Mn3 (red) and $\mathrm{Mn} 1$ (black)/Mn4 (green) waves with closer propagation are coupled for simplicity. A single unit is shown for Mn1/Mn4 sites while longer sections are shown for Mn2/Mn3. Magnetic phase factors (relative shifts of the waves) are indicated.

$k_{0}=\left[\begin{array}{lll}0 & 0 & 0\end{array}\right]$, where it develops a collinear magnetic structure with all magnetic moments along the easy $c$ axis. This magnetic structure refined from NPD data collected at $40 \mathrm{~K}$ is shown in Fig. 3a. It describes AFM (101) planes of MnA sites (black dashed lines). MnB (blue) sites align AFM with Mn1 (black), according to dominant direct $\mathrm{d}^{5}-\mathrm{d}^{5}$ interactions through octahedral face sharing. ${ }^{14}$ The need for FM interactions between $\mathrm{MnB}$ and Mn3 (red)/Mn4 (green) A sites induces magnetic frustration. Below $T_{\mathrm{M}}$, the magnetic frustration of $\mathrm{MnB}$ sites (vide infra), induces a sinusoidal modulation of the magnetic moments into a complex SDW magnetic structure with $k_{\mathrm{M}}=\left[\begin{array}{lll}k_{x} & 0 & k_{z}\end{array}\right]$. This modulation involves the continuous evolution of the propagation vector towards $k_{x}=1 / 3$ and $k_{z}=-1 / 6$, where they are locked below $10 \mathrm{~K}$ (Fig. 2 bottom panel). Averaged magnetic moments $\left(\mu_{\mathrm{av}}=\mu / 2 \pi\right)$ evolve progressively throughout the complete temperature range, reaching a maximum value of 3.81(1) $\mu_{\mathrm{B}}$. This value corresponds to $76.2 \%$ of the ideal $2 \mathrm{~S}=5$ value for $\mathrm{Mn}^{2+}$, in line with the change in magnetic entropy estimated from heat capacity (see ESI $\dagger$ ).

The low temperature magnetic structure, schematized in Fig. $3 b$, can be described as a SDW with $k_{\mathrm{L}}=\left[\begin{array}{lll}1 / 3 & 0 & -1 / 6\end{array}\right]$ and magnetic moments modulated along the $c$ easy axis, varying between zero and saturated values of 5.1 (1) $\mu_{\mathrm{B}}$. Two different types of sine waves propagating along the $a$ axis alternate along $c$, showing up-up-0-down-down-0 (UU0DD0) and 3up-3down (sinusoidal) patterns. Similarly complex frustrated magnetic structures are reported in the only oxynitride A-site manganite with Ta, $\mathrm{MnTaO}_{2} \mathrm{~N}^{15}{ }^{15}$ The magnetic frustration between $\mathrm{A}$ and $\mathrm{B}$ sites is the driving force for the modulation of these unusual SDW in A-site manganites with TPv structure (see below and ESI $\dagger$ for details). 
The most distinctive point of both TPv HP- $\mathrm{Mn}_{3} \mathrm{MnB}_{2}{ }_{2} \mathrm{O}_{9}$ phases $\left(\mathrm{B}^{\prime}=\mathrm{Ta}\right.$ and $\left.\mathrm{Nb}\right)$ is their magnetic frustration. While the $\mathrm{Nb}$ compound showed a larger frustration index (6.42), its collinear $k_{0}$ phase was dominant down to lower $T_{\mathrm{M}}=27.8 \mathrm{~K}$. As a result, the magnetic moment of $\mathrm{Mn}^{2+}$ spins increased in this $k_{0}$ phase for $\mathrm{HP}-\mathrm{Mn}_{3} \mathrm{MnNb}_{2} \mathrm{O}_{9}$ to maximum values of $2.68(1) \mu_{\mathrm{B}}$ before modulating into the SDW, while the Ta compound reported here reaches only $2.50(1) \mu_{\mathrm{B}}$ in the collinear phase. The reason for the earlier modulation of the magnetic moments in $\mathrm{HP}-\mathrm{Mn}_{3} \mathrm{MnTa}_{2} \mathrm{O}_{9}$ compared to the $\mathrm{Nb}$ analogue is the larger constraint function, ${ }^{16}$ i.e. the energy ratio between the ground SDW and the hypothetical non-modulated collinear phases. The energy of both magnetic phases can be estimated using a classical spin description as $E_{\mathrm{f}}\left(k_{0}\right)=\Sigma J_{i j}{ }^{*} s_{i}^{*} s_{j}$, where $J_{i j}$ is the spin exchange parameter and $s_{i}$ and $s_{j}$ are the magnetic moments of $i$ and $j$ sites. Considering a hypothetical AFM nonmodulated phase at low temperature with all equivalent $\left(\mu_{\mathrm{av}}\right)$ magnetic moments $2.50 \mu_{\mathrm{B}}, E_{\mathrm{f}}\left(k_{0}\right)=1350^{*} \mathrm{~J}$. The spin modulation minimizes the number of frustrated (FM MnB-MnA) interactions in the $k_{\mathrm{L}}$ phase, which decrease from 12 to 5 in each unit cell (see SF4, ESI $\dagger$ ). Therefore, accounting for the 18 cells per magnetic cell and the different magnetic moments in the UUODD0 waves $\left(4.33 \mu_{\mathrm{B}}\right)$ and in the sinusoidal waves (5 or $2.5 \mu_{\mathrm{B}}$ ), the estimated $E_{\mathrm{f}}\left(k_{\mathrm{L}}\right)=1177.2^{*} \mathrm{~J}$. The ratio $F=E_{\mathrm{f}}\left(k_{0}\right) /$ $E_{\mathrm{f}}\left(k_{\mathrm{L}}\right)=1.15$, suggests maximum values of $2.2 \mu_{\mathrm{B}} / \mathrm{Mn}^{2+}$ would be reached in the hypothetical non-modulated structure to keep the same energy, while the modulation of the magnetic moments allows their partial saturation with averaged moments near $80 \%$ of their ideal value. Therefore, the magnetic frustration between $\mathrm{A}$ and $\mathrm{B}$ sites is confirmed to be the driving force for the modulation of these unusual SDW in A-site manganites with TPv structure. A similar estimation for HP$\mathrm{Mn}_{3} \mathrm{MnNb}_{2} \mathrm{O}_{9}$ results in $F=1.32$, thus showing a larger frustration.

High temperature XRD studies revealed the reversibility of the structural phase transition back to the room pressure polymorph $\mathrm{Mn}_{4} \mathrm{Ta}_{2} \mathrm{O}_{9}$ upon heating $\mathrm{HP}-\mathrm{Mn}_{3} \mathrm{MnTa}_{2} \mathrm{O}_{9}$ at room pressure. As shown in Fig. 4a, it is a first order transition starting at $625{ }^{\circ} \mathrm{C}$ and completed at $780{ }^{\circ} \mathrm{C}$. A comparison between both structures is presented in Fig. 4a. The cornersharing B-site scaffold for the HP TPv phase is highlighted (blue $\mathrm{MnBO}_{6}$ and orange $\mathrm{TaO}_{6}$ octahedra). Compared with $\mathrm{Mn}_{4} \mathrm{Ta}_{2} \mathrm{O}_{9}$, the main structural difference is the antiphase rotation between the $\mathrm{TaO}_{6}$ octahedra ending up in the characteristic face sharing in the room pressure polymorph. These changes in connectivity have a strong effect in the optical properties.

Kubelka-Munk plots of our experimental UV-vis reflectance spectra (Fig. 4b) show a $\Delta E_{\text {gap }}=0.9 \mathrm{eV}$ from the $\mathrm{Mn}_{4} \mathrm{Ta}_{2} \mathrm{O}_{9}$ precursor $\left(E_{\text {gap }}=3.5 \mathrm{eV}\right)$ to the $\mathrm{Mn}_{3} \mathrm{MnTa}_{2} \mathrm{O}_{9} \mathrm{TPv}$ high pressure phase $\left(E_{\text {gap }}=2.6 \mathrm{eV}\right)$. DFT $+U(U=5 \mathrm{eV})$ calculations in a ferromagnetic configuration were performed for both polymorphs (Fig. 4c). A $E_{\text {gap }}=2.4 \mathrm{eV}$ was obtained for RP$\mathrm{Mn}_{4} \mathrm{Ta}_{2} \mathrm{O}_{9}$ in accordance with previous reports. ${ }^{17} \mathrm{HP}$ $\mathrm{Mn}_{3} \mathrm{MnTa}_{2} \mathrm{O}_{9}$ shows a reduced $E_{\text {gap }}=1.5 \mathrm{eV}$. Although both calculated gaps are underestimated by $\approx 1 \mathrm{eV}$ from their
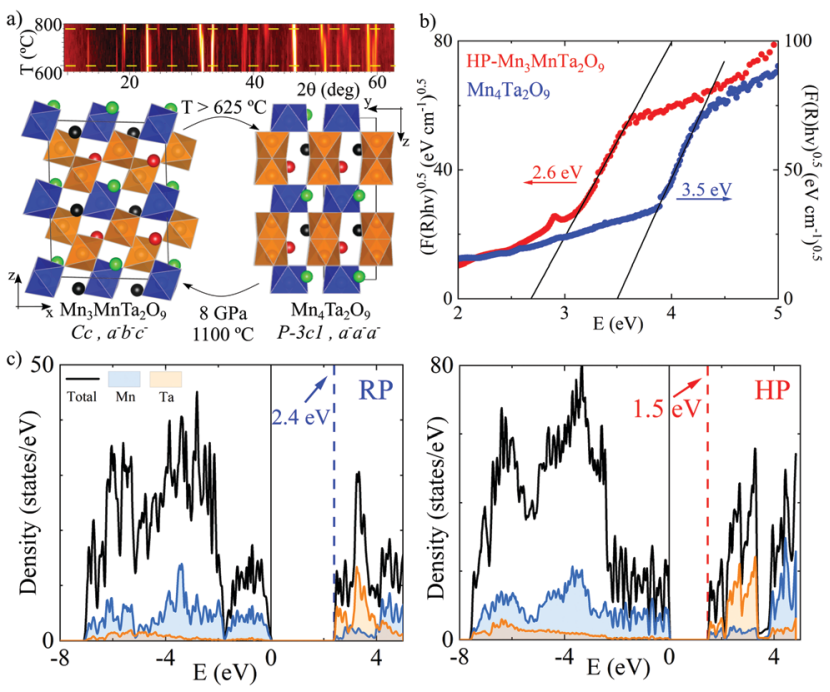

Fig. 4 (a) XRD thermodiffraction patterns showing a room pressure phase transition from the $\mathrm{Cc}$ TPv structure of $\mathrm{HP}-\mathrm{Mn}_{3} \mathrm{MnTa}_{2} \mathrm{O}_{9}$ to the $P \overline{3} \mathrm{c} 1$ structure of $\mathrm{Mn}_{4} \mathrm{Ta}_{2} \mathrm{O}_{9}$. The transition temperature range $\left(625-780{ }^{\circ} \mathrm{C}\right)$ is delimited with dashed lines. Projections along [010] of $\mathrm{HP}-\mathrm{Mn}_{3} \mathrm{MnTa}_{2} \mathrm{O}_{9}$ (left) and [100] of $\mathrm{Mn}_{4} \mathrm{Ta}_{2} \mathrm{O}_{9}$ (right) structures compared below. (b) UV-Vis data showing $25 \%$ band gap reduction. (c) Density of states calculated for the room (left) and high-pressure (right) polymorphs.

experimental values, they show the same $\Delta E=0.9 \mathrm{eV}$ gap shift. Moreover, the $E_{\text {gap }}$ reduction in $\mathrm{Mn}_{3} \mathrm{MnTa}_{2} \mathrm{O}_{9}$ is mainly due to the Ta octahedra, lying at the bottom of the conduction band that shows a red shift. This is commonly related to the change in connectivity between both polymorphs, the denser being prone to easier carrier hopping. The most critical structural reorganization involves the collapsing of face-sharing electronblocking $\mathrm{Ta}_{2} \mathrm{O}_{9}$ dimers $\left(d_{(\mathrm{Ta}-\mathrm{Ta})}=3.08 \AA\right)$ and edge-sharing Ta-Mn links $\left(d_{(\mathrm{Ta}-\mathrm{Mn})}=3.17 \AA\right)$ in the RP form, for face sharing Mn-Ta bridges $\left(d_{(\mathrm{Mn}-\mathrm{Ta})}=3.03 \AA\right)$ in the HP-polymorph, more prompt to delocalization. $\mathrm{Mn}_{3} \mathrm{TeO}_{6}$ also shows a similar reduction in the band gap between the room $\left(E_{\text {gap }}=2.6 \mathrm{eV}\right)$ and the high-pressure polymorphs $\left(E_{\text {gap }}=1.8 \mathrm{eV}\right) .{ }^{18}$ The differences between both structures in $\mathrm{Mn}_{3} \mathrm{TeO}_{6}$ are also due to a drastic structural reorganization of the polyhedral connectivity. A similar explanation has been found for the gap variation between light-harvesting lead iodide perovskite-derived compounds. ${ }^{19}$ In the case of the here discussed modifications of $\mathrm{RP}-\mathrm{Mn}_{4} \mathrm{Ta}_{2} \mathrm{O}_{9}$ and $\mathrm{HP}-\mathrm{Mn}_{3} \mathrm{MnTa}_{2} \mathrm{O}_{9}$, the gap reduction is mainly promoted by the change in the $\mathrm{TaO}_{6}$ octahedra connectivity.

\section{Conclusions}

In conclusion a new $\mathrm{HP}-\mathrm{Mn}_{3} \mathrm{MnTa}_{2} \mathrm{O}_{9} \mathrm{~A}$-site manganite with TPv structure and 1:2 B-site order of $\mathrm{Mn}$ and Ta has been prepared under HPHT conditions. This is notable as it represents only the second transition-metal-only compound ever reported to show this $C c$ structure, suggesting a new complete family of functional oxides is accessible. The complex magnetic behavior arises from highly frustrated $\mathrm{Mn}-\mathrm{Mn}$ interactions 
giving rise to an unusual SDW with propagation vector $k=\left[\begin{array}{lll}1 / 3 & 0 & -1 / 6\end{array}\right]$ locked at low temperatures, dictated by the B-site cation order and reflecting the key role of the triangular antiferromagnetic sublattices. The metastable HP$\mathrm{Mn}_{3} \mathrm{MnTa}_{2} \mathrm{O}_{9} \mathrm{TPv}$ polymorph transforms back into the ambient $\mathrm{Mn}_{4} \mathrm{Ta}_{2} \mathrm{O}_{9}$ structure above $625{ }^{\circ} \mathrm{C}$. The connectivity changes between the room- and the high-pressure polymorph promotes a band gap reduction as observed in UV-vis measurements and further confirmed by DFT calculations.

\section{Author contributions}

The study was designed by A. M. A. L. Synthesis was performed by E. S. M. Bulk magnetism and heat capacity data were measured and analyzed by E. S. M. and A. M. A. L. Neutron diffraction data were collected and analyzed by E. S. M., A. M. A. L. and C. R. DFT calculations were performed by O. M. The paper was written by E. S. M. and A. M. A. L. with collaborations from all authors.

\section{Conflicts of interest}

There are no conflicts to declare.

\section{Acknowledgements}

We thank support from ANR AMANTS project (19-CE08-0002-01) and the ILL for beamtime at D20 (doi: 10.5291/ILL-DATA.EASY-858) The Chevreul Institute (FR 2638), Region Hauts-de-France, and FEDER are acknowledged for funding the X-ray diffractometers, the "LEGO" multianvil-press and the PPMS magnetometer.

\section{Notes and references}

1 S. Vasala and M. Karppinen, Prog. Solid State Chem., 2015, 43, 1-36.

2 A. T. Mulder, N. A. Benedek, J. M. Rondinelli and C. J. Fennie, Adv. Funct. Mater., 2013, 23, 4810-4820.

3 K.-I. Kobayashi, T. Kimura, H. Sawada, K. Terakura and Y. Tokura, Nature, 1998, 395, 677-680.

4 W.-t. Chen, M. Mizumaki, H. Seki, M. S. Senn, T. Saito, D. Kan, J. P. Attfield and Y. Shimakawa, Nat. Commun., 2014, 5, 3909.
5 M. Markkula, A. M. Arévalo-López, A. Kusmartseva, J. A. Rodgers, C. Ritter, H. Wu and J. P. Attfield, Phys. Rev. B: Condens. Matter Mater. Phys., 2011, 84, 094450.

6 A. M. Arévalo-López, G. M. McNally and J. P. Attfield, Angew. Chem., Int. Ed., 2015, 54, 12074-12077.

7 E. Solana-Madruga, A. M. Arévalo-López, A. J. Dos santosGarcía, E. Urones-Garrote, D. Ávila-Brande, R. Sáez-Puche and J. P. Attfield, Angew. Chem., Int. Ed., 2016, 55, 9340-9344.

8 S. V. Ovsyannikov, A. M. Abakumov, A. A. Tsirlin, W. Schnelle, R. Egoavil, J. Verbeeck, G. Van Tendeloo, K. V. Glazyrin, M. Hanfland and L. Dubrovinsky, Angew. Chem., Int. Ed., 2013, 52, 1494-1498.

9 D. D. Khalyavin, R. D. Johnson, P. Manuel, A. A. Tsirlin, A. M. Abakumov, D. P. Kozlenko, Y. Sun, L. Dubrovinsky and S. V. Ovsyannikov, Phys. Rev. B, 2018, 98, 014426.

10 E. Solana-Madruga, C. Ritter, C. Aguilar-Maldonado, O. Mentré, J. P. Attfield and Á. M. Arévalo-López, Chem. Commun., 2021, 57, 8441-8444.

11 J. Rodriguez-Carvajal, Phys. B, 1993, 192, 55-69.

12 R. D. Shannon and C. T. Prewitt, Acta Crystallogr., Sect. B: Struct. Crystallogr. Cryst. Chem., 1969, 25, 925-946.

13 E. F. Bertaut, L. Corliss and F. Forrat, J. Phys. Chem. Solids, 1961, 21, 234-251.

14 J. B. Goodenough, Magnetism and the Chemical Bond, New Wiley, New York, 1963, pp. 180-181.

15 C. Tassel, Y. Kuno, Y. Goto, T. Yamamoto, C. M. Brown, J. Hester, K. Fujita, M. Higashi, R. Abe, K. Tanaka, Y. Kobayashi and H. Kageyama, Angew. Chem., Int. Ed., 2015, 54, 516-521.

16 D. Dai and M. H. Whangbo, J. Chem. Phys., 2004, 121, 672-680.

17 N. Narayanan, A. Senyshyn, D. Mikhailova, T. Faske, T. Lu, Z. Liu, B. Weise, H. Ehrenberg, R. A. Mole, W. D. Hutchison, H. Fuess, G. J. McIntyre, Y. Liu and D. Yu, Phys. Rev. B, 2018, 98, 134438.

18 Á. M. Arévalo-López, E. Solana-Madruga, C. AguilarMaldonado, C. Ritter, O. Mentré and J. P. Attfield, Chem. Commun., 2019, 55, 14470-14473.

19 M. E. Kamminga, G. A. de Wijs, R. W. A. Havenith, G. R. Blake and T. T. M. Palstra, Inorg. Chem., 2017, 56, 8408-8414. 